\title{
Psychosocial Needs of Bereaved Spouses in Nigeria: Implications for Grief Counselling Intervention
}

\author{
Shuaib A. Muhammed
}

\begin{abstract}
Spousal death is a traumatic life event which engenders different reactions. It becomes more challenging when psychosocial needs are inadequate. This study examined the psychosocial needs of bereaved spouses in Nigeria. The research method adopted for this study was descriptive survey. The population of the study consisted of 1,924,301 bereaved spouses in Nigeria. Purposive and proportional sampling techniques were adopted in selecting a total sample of 1,594 bereaved spouses across the six geo-political zones in Nigeria. The Psychosocial Needs of Bereaved Spouses Scale was used for data collection. Means, percentages, rank order, t-test, and Analysis of Variance (ANOVA) statistical measures were used to analyze the data collected for the study. The findings of the study revealed that respondents needed to acquire a job to sustain the family, raise finances for family upkeep, pay house bills and deal with widowhood isolation, among others. Also, age at bereavement, length of years of loss and nature of death had significant influences on respondents' psychosocial needs, while gender and religious affiliations had no significant influence on the psychosocial needs of the respondents. The study concluded that respondents' psychosocial needs were high. The implication is that bereaved spouses need better psychosocial supports to facilitate better adjustments. Based on the findings of the study, it was recommended, among others, that counsellors should provide relevant community-based intervention programs and support services to assist bereaved spouses of different age groups, length of years of loss and nature of death, religion, and gender to meet their varying needs.
\end{abstract}

Key words: bereaved spouses, counselling, grief, psychosocial needs, Nigeria.

Muhammed Shuaib Abolakale is a Lecturer II in the in the Department of Counsellor Education, University of Ilorin, Nigeria. He obtained his Bachelor, Master and Ph.D. Degree in Educational Guidance and Counselling. Dr. Muhammed has a propensity for teaching, consultancy, advocacy, organising and supervising practicum activities, community service and doing research work. His research efforts have settled around a number of issues surrounding dating, courtship and sexual behaviours of undergraduates, positive parenting and family counselling, behaviour problems intervention in schools, counselling practicum development and grief and bereavement in diverse population and other general counselling-related issues. Recent publications include: Oniye, A. O., BoluSteve, F. N.; Muhammed, S. A. \& Soyemi, O. S. (2016) Causes of Nagging in Marriage as Expressed by Married Women in Oyo State, Nigeria. Journal of Issues and Practice in Education, 8 (1), 40-49. ISSN 1821 5548; Muhammed, S. A., Oniye A.O., \& Olamilekan, A. S. (2019). Impact of Counselling Practicum on Trainees in University of Ilorin Nigeria Anatolian Journal of Education, 4(2). e-ISSN: 2547-9652. https://doi.org/10.29333/aje.2019.427a. www.e-aje.net 


\section{Introduction}

The loss of a loved one is generally perceived as a traumatic and discerning life experience which engenders different reactions. For many individuals, it means that some life experiences will never remain as before and living without the deceased becomes practically difficult, while others will normalize over time. Some individuals are able to reconcile and adjust to normal life within a short time, while others struggle for a long time. However, for people who do not reconcile, adjust and adapt normally to their bereavement, grieving can become challenging resulting in a poor adjustment and low quality of life. Bereavement is connected with physiological, emotional, psychological and health challenges. Therefore, it can cause physical, cognitive, and emotional reactions such as sleeplessness, loss of energy, loss of appetite and loss of meaning for life (BUPA Health Information Service, 2004).

Spousal death may create a chronic grief experience that can result in negative health outcomes including sleep disruption, depression, anxiety, defective immune function and poor physical health (Bruce, Kim, Leaf, \& Jacobs, 1990; Phillips, Carroll, Burns, Ring, Macleod, \& Drayson, 2006; Monk, Begley, Billy, Fletcher, Germain, Mazumdar \& Zarotney, 2008). Boyle, Feng and Raab (2011) also posited that widowhood experience is a major risk factor that can increase the mortality rate of the surviving spouse. After the death of a spouse, the bereaved spouse would not only need to cope with the loss, but may also need to meet certain needs such as making important decisions and handling responsibilities that were once dispersed between the two spouses. This assertion suggests that for a bereaved spouse to handle daily decisions and responsibilities earlier shared by two individuals there will be a serious challenge of meeting the varying psychosocial needs to survive and adjust to the loss of the partner.

Researchers such as Prigerson and Jacobs (2001), Stroebe and Schut (2001), Hansson and Stroebe (2007), Barreto, Yi \& Soler (2008), Tomarken, Holland, Schachter, Vanderwerker, Zuckerman and Nelson (2008) have shown that the death of a loved one is among the major psychosocial challenges influenced by available primary support groups and the social environment which is classified on axis IV of the multi-axial classification (DSM IV), a Diagnostic and Statistical Manual of Mental Disorder developed by the American Psychiatric Association which measures the psychosocial and environmental factors contributing to mental disorder.

Usually bereavement, especially spousal-related bereavement, is accompanied by many stress factors including economic and financial challenges, security matters, disruption in socialeconomic structures and roles, violence, persecution and discrimination and vulnerability to violent acts (International Organization for Migrations, IOM 2010). Often, these events bring about a variety of feelings and reactions including grief, loss and depression, a sense of inferiority, isolation, depression, anger and insecurity. The IOM (2010) also posited that the psychosocial stressors caused by death related-grief are not of pathological or biological in nature, most often, they are the evidence of inability of people to meet their needs in order to cope with their unpleasant conditions.

Hence, bereaved spouses require numerous needs to respond to the new situation of widowhood in order to prevent or reduce the common condition of suffering and psychosocial uneasiness, which may in turn produce unhealthy individuals, families and communities in the 
long-run. Therefore, to acquire a better adjustment and achieve post-traumatic growth after bereavement, the psychological and social needs of bereaved spouses must be attended to. Psychosocial needs can be described as social, emotional, mental and spiritual requirements of an individual in order to adjust, live quality life and contribute to the development of the society (IOM, 2010). Khaleed (2005) identified five psychosocial needs of widows as social needs, economic needs, educational needs, psychological needs and health needs. It is the view of this author that ability to meet these needs would help bereaved spouses live a fulfilled life and gain better adjustment. Bereaved spouses, however, differ widely in their experience of adjustment to loss. Some may have experience of mild depression and anxiety amidst the first 3 to 6 months following loss, whereas others may experience severe, debilitating and persistent symptoms, including complicated and prolonged grief (Prigerson, Vanderwerker \& Maciejewski, 2008).

Needs of individual can be viewed as objective and physical such as food shelter and clothing, or they can be subjective and psychological such as the need for self-esteem, love and self-actualization. This concept of need can also be viewed from a psychological theory propounded by Abraham Maslow in 1943. According to Maslow (1954), the hierarchy of needs can be likened to shape of a pyramid, with the most fundamental levels of needs at the bottom and the lesser needs at the top (see Figure 1 below).

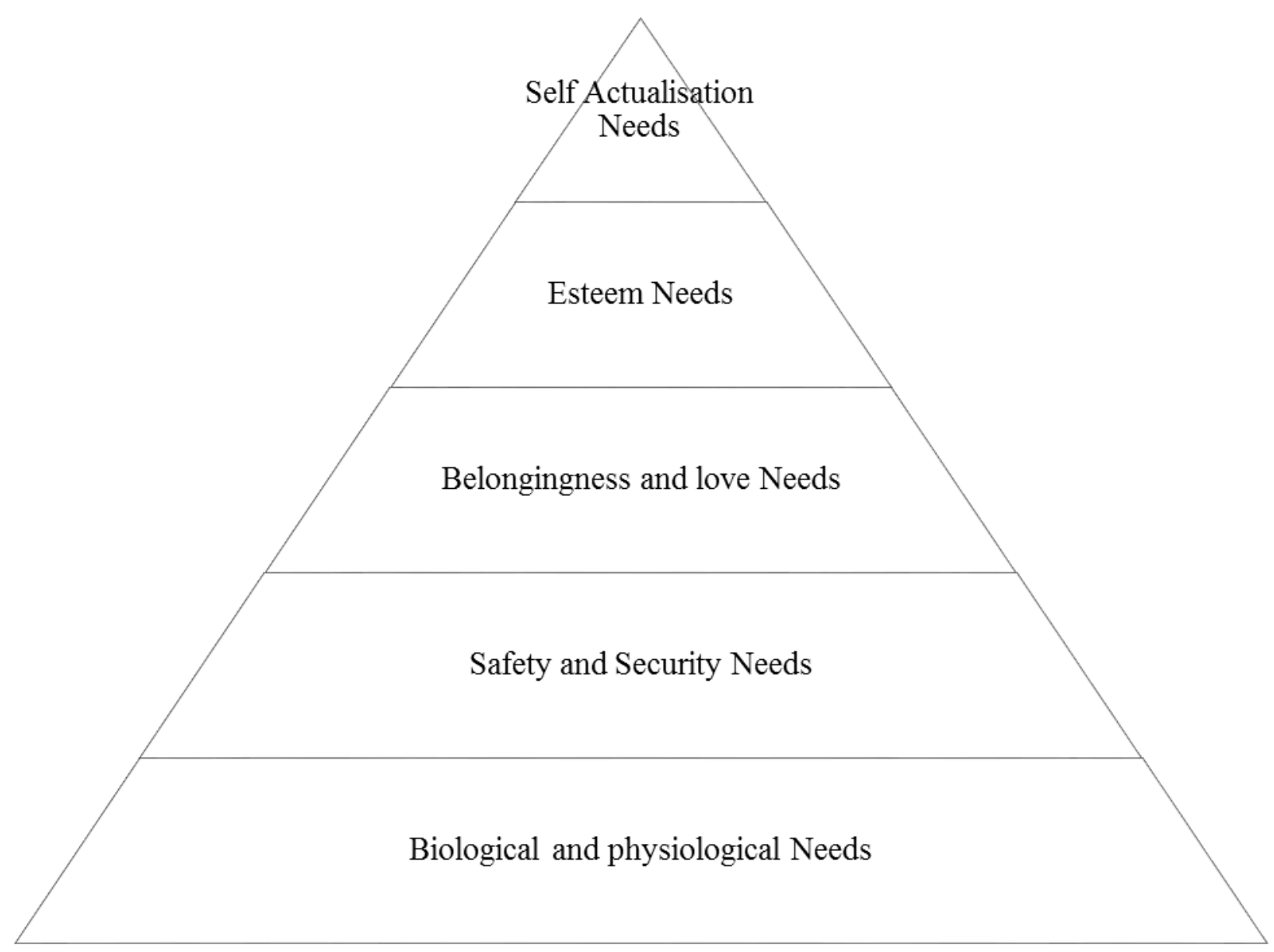

Figure 1: Abraham Maslow Hierarchy of Needs (1954) 
The basic needs that are contained in the top four layers of the pyramid are what Maslow called "Deficiency needs" or "D-needs", including self-esteem, belongingness and love, safety and security and self-actualization needs. According to Maslow, if these "Deficiency Needs" are not met, with exceptions to physiological needs (air, food water, shelter, warmth sleep among others), an individual feels anxious and tense. Maslow's theory suggests that individual most basic level of needs must be accomplished before he or she desires to acquire higher level needs. Maslow described the motivation to strive for higher needs and constant betterment with the term "Meta-motivation". According to Maslow (1954) "Meta-motivated" people are motivated by Bneeds (Being Needs), instead of D-Needs (Deficiency Needs).

The study of psychosocial need, therefore, looks in to people's interconnected social and psychological basic level of needs and thus addressing them in an integrated manner. Consideration of the interconnectivity of the psychological and social requirements is necessary in such situations where it is impossible to separate the social, psychological-emotional, and physiological consequences of the events (like spousal death). Psychosocial needs of bereaved spouses can thus be described as psychological, social, physiological and spiritual requirements of the bereaved in order to adjust better to the situations of life, live quality life and contribute to development of the society. Considering the widowhood experiences rooted in different cultures in Nigeria, this study examined the psychosocial needs of bereaved spouses in Nigeria. Therefore, questions as to what are the psychosocial needs of bereaved spouses in Nigeria? How do demographic variables such as age at bereavement length of years of loss and nature of death interact with psychosocial needs of bereaved individual? were raised to guide the conduct of the study. Finding answers to these questions will help to establish empirical evidence on the type of psychosocial intervention that is needed by bereaved spouses.

The following null hypotheses were tested in the study:

1. Psychosocial needs of bereaved spouses in Nigeria will not significantly differ based on age.

2. Psychosocial needs of bereaved spouses in Nigeria will not significantly differ based on gender.

3. Psychosocial needs of bereaved spouses in Nigeria will not significantly differ based on religious affiliation.

4. Psychosocial needs of bereaved spouses in Nigeria will not significantly differ based on nature of death.

5. Psychosocial needs of bereaved spouses in Nigeria will not significantly differ based on length of years of loss. 


\section{Materials and Method}

The research design adopted for the study is the descriptive survey. The population for the study comprised all bereaved spouses in Nigeria while the target population is made up of bereaved spouses drawn from selected states in the six geopolitical zones in Nigeria. According to the National Bureau of Statistics (NBS, 2012), the total population of bereaved spouses in Nigeria is estimated to be 1,924,301. Using the Research Advisor's (2006) "Sample Size Determination Table, a sample size of 1,536 was recommended for a population size of this magnitude. However, 1,594 respondents were chosen for the study (see table 1) to cater for attrition. This sample size was determined at $95 \%$ confidence interval, and $2.5 \%$ Margin of error.

The procedures that were used for selecting sample for this study are purposive sampling and proportional sampling techniques. The purposive sampling method was used to select six states that have the highest number of widowed persons from each of the six geopolitical zones in Nigeria. The states are Borno, Lagos, Enugu, Kano, Benue, and Delta. Purposive sampling technique was considered appropriate for the study because it is a form of non-probability sampling technique which is characterized by the use of judgment and deliberate effort to obtain representative samples by including presumable typical areas of groups in the sample.

The proportional sampling technique was then used to select a representative sample of 1,594 bereaved spouses from the aforementioned states namely: Borno (171), Lagos (371), Enugu (255), Kano (329), Benue (207) and Delta (261) in proportion to the population of bereaved spouses in each state (see Table 1).

\section{Table 1: Proportion Percentage of Bereaved Spouses in the Target States in Nigeria}

\begin{tabular}{lllll}
\hline S/N & States & $\begin{array}{l}\text { Population } \\
\text { of Bereaved Spouses }\end{array}$ & Proportion percentage \% & Sample \\
\hline 1 & Borno & 56,649 & 10.7 & 171 \\
2 & Benue & 68,486 & 13.0 & 207 \\
3 & Delta & 86,629 & 16.4 & 261 \\
4 & Enugu & 84.151 & 16.0 & 255 \\
5 & Kano & 108,880 & 20.6 & 329 \\
6 & Lagos & 123,291 & 23.3 & 371 \\
& Total & $\mathbf{5 2 8 , 0 8 0}$ & $\mathbf{1 0 0 . 0}$ & $\mathbf{1 5 9 4}$ \\
\hline
\end{tabular}

Proportional sampling was considered appropriate in choosing the respondents for the study because the population of respondents from the selected states is not equal. Proportional sampling, according to James (2010), provides the researcher the opportunity to select respondents at random from the subgroup in proportion to the size of the group in the total population. This was done by selecting bereaved spouses from places such as registered widow's organizations, women's associations, religious groups/ gathering, cooperative society meetings, government offices and individual homes. 
The main instrument that was used to collect data for this study is a questionnaire titled "Psychosocial Needs of Bereaved Spouses Scale" (PNBSS). The Psychosocial Need of Bereaved Spouses Scale (PNBSS) is a researcher's designed instrument. The items on the scale were drawn from the review of literature such as Widowhood Assessment Need by Khaleed (2005). The PNBSS is a 20-item questionnaire consisting of two (2) sections, A and B. Section A contains the biographic data which includes personal information of the respondents namely age at bereavement, gender, religious affiliation and nature of death. Section B of the scale contains four (4) subsections containing items relating to the economic, social, health and psychological needs of bereaved spouses in Nigeria. The scale was patterned after the four-point Likert-type rating scale format of Always True (AT, 4 points), Mostly True (MT, 3points), Somewhat True (ST, 2 points) and Not True (NT, 1point).

The instrument (PSNBSQ) was validated by experts in the Departments of Counsellor Education and Behavioural Sciences for expert vetting and assessment. The experts' amendments and suggestions were affected when preparing the final draft of the instrument. All the five experts adjudged the instrument as correctly measuring the variable of interest; thus ascertaining the content validity of the instrument. The reliability of the instrument was ascertained through the test re-test reliability method. The correlation co-efficient obtained was 0.83 at 0.05 alpha level of significance. The data obtained were analyzed using percentages, $\mathrm{t}-$ test Analysis of Variance statistical analysis to test the null hypothesis formulated.

\section{Results}

The distributions based on the characteristics of the respondents in terms of gender, age at bereavement, religious affiliation, nature of death and length of years of loss were presented in this section.

Table 3: Distribution of Respondents by Gender, Age at Bereavement, Religious Affiliation, Nature of Death and Length of Years of Marriage

\begin{tabular}{lccc}
\hline S/N & Variables & Frequency & Percentage \% \\
\hline 1. & 381 & 23.9 \\
& Gender & 1213 & 76.1 \\
Male & $\mathbf{1 5 9 4}$ & $\mathbf{1 0 0 . 0}$ \\
Female & & \\
Total & 424 & 26.6 \\
Age at bereavement & 472 & 29.6 \\
30 years or less & 307 & 19.3 \\
31 - 40 years & 391 & 24.5 \\
41-50 years & $\mathbf{1 5 9 4}$ & $\mathbf{1 0 0 . 0}$ \\
Above 50 years & & \\
Total & 67 & 4.2 \\
& Religion & 836 & 52.4 \\
ATR & 691 & 43.4 \\
Christianity & $\mathbf{1 5 9 4}$ & $\mathbf{1 0 0 . 0}$
\end{tabular}


Muhammed

4.

\section{Nature of Death}

Sudden

Anticipated

Others

Total

5.

Length of years of loss

Less than a year

1-5years

6-10 years

Above 10 years

Total

$\begin{array}{lr}662 & 41.5 \\ 562 & 35.3 \\ 370 & 23.2 \\ \mathbf{1 5 9 4} & \mathbf{1 0 0 . 0} \\ & \\ 409 & 25.7 \\ 533 & 36.6 \\ 438 & 27.5 \\ 164 & 10.3 \\ \mathbf{1 5 9 4} & \mathbf{1 0 0 . 0}\end{array}$

Table 3 presents the percentage distribution of respondents based on gender, age at bereavement, religion, nature of death and length of years of loss. The information on the table indicates that $381(23.9 \%)$ of the respondents were males while $1213(76.1 \%)$ were females. Also, $424(26.6 \%)$ of the respondents were below 30 years while $472(29.6 \%)$ fall between 31 and 40 years, $307(19.3 \%)$ were between 41 and 50 years while 391 (43.4\%) of the respondents were above 50 years. The result further reveals that $67(4.2 \%)$ of the respondents belong to African Traditional Religion, 836 (52.4\%) were Christians while 691 (43.4\%) of the respondents were Muslims. The result also revealed that $662(41.5 \%)$ of the respondents lost their spouse through sudden death, $562(35.3 \%)$ had anticipated the death of their spouses while $370(23.2 \%)$ suffered the death of their spouses through other means. Finally, the table shows that at the time of data collection, 409 (25.7\%) of the respondents lost their spouses less than a year, $533(36.6$ $\%)$ lost their spouses 1-5years, $438(27.5 \%)$ lost their spouses 6-10 years while $164(10.3 \%)$ of the respondents lost their spouses more than 10 years back.

\section{Research Question}

What are the psychosocial needs of bereaved spouses in Nigeria?

Table 5: Mean and Rank Order Analysis of Psychosocial Needs of Bereaved Spouses in Nigeria

\begin{tabular}{llll}
\hline Item No & Item & Mean & Rank \\
\hline 1 & get a job to sustain the family & 2.99 & $1^{\text {st }}$ \\
3 & raise finances for family up keep & 2.93 & $2^{\text {nd }}$ \\
2 & be able to pay house bills & 2.90 & $3^{\text {rd }}$ \\
16 & deal with widowhood isolation & 2.79 & $4^{\text {th }}$ \\
14 & have access to routine medical treatment & 2.79 & $4^{\text {th }}$ \\
9 & have access to family support & 2.79 & $4^{\text {th }}$ \\
20 & achieve self esteem & 2.76 & $7^{\text {th }}$ \\
8 & have access to social support & 2.74 & $8^{\text {th }}$ \\
12 & have good nutrition & 2.73 & $9^{\text {th }}$ \\
19 & cope with the loss & 2.72 & $10^{\text {th }}$ \\
4 & access to regular Income & 2.72 & $10^{\text {th }}$ \\
7 & maintain social relationship & 2.72 & $10^{\text {th }}$ \\
\hline
\end{tabular}




\begin{tabular}{llll}
\hline 13 & get good sleep & 2.70 & $13^{\text {th }}$ \\
11 & have access to regular medical check up & 2.68 & $14^{\text {th }}$ \\
6 & achieve self confidence & 2.64 & $15^{\text {th }}$ \\
15 & have access to regular recreation facilities/opportunities & 2.64 & $15^{\text {th }}$ \\
5 & receive training in order to establish personal projects. & 2.63 & $17^{\text {th }}$ \\
10 & be re-married & 2.53 & $18^{\text {th }}$ \\
18 & cope with loneliness & 2.52 & $19^{\text {th }}$ \\
17 & be safe & 2.51 & $20^{\text {th }}$ \\
\hline
\end{tabular}

Table 5 shows the means and rank order analysis of responses on psychosocial needs of bereaved spouses in Nigeria. The results revealed that all the items ranked above 2.50 cut off point which is an indication of the fact that respondents perceived all the items on the instrument as a measure of their psychosocial needs. However, items 1, 3, 2, 16, 14 and 9 ranked as the five top items. Item 1 which states that as a bereaved spouse, I need to "get a job to sustain the family" ranked $1^{\text {st }}$ with a mean score of 2.99 , item 3 which states that as a bereaved spouse, I need to "raise finances for family up keep" ranked $2^{\text {nd }}$ with a mean score of 2.93 , item 2 which states that as a bereaved spouse, I need to "be able to pay house bills" ranked $3^{\text {rd }}$ with a mean score of 2.90 , items 16, 14 and 9 which states that as a bereaved spouse, I need to "deal with widowhood isolation" "have access to routine medical treatment" and have access to family support" ranked $4^{\text {th }}$ with a mean score of 2.79 respectively, and item 20 which states that as a bereaved spouse, I need to "achieve self-esteem" ranked $7^{\text {th }}$ with a mean score of 2.76 .

The results further revealed that items 15, 5, 10, 18 and 17 ranked as the least five items respectively. Item 15 which states that as a bereaved spouse, I need to "have access to regular recreation facilities/opportunities ranked $16^{\text {th }}$ with a mean score of 2.64 , item 5 , which states that as a bereaved spouse, I need to "receive training in order to establish personal projects.

" ranked $17^{\text {th }}$ with a mean score of 2.63 , item 10 , which states that as a bereaved spouse, I need to "be re-married" ranked $18^{\text {th }}$ with a mean score of 2.53 , item 18 , which states that as a bereaved spouse, I need to "cope with loneliness ranked $19^{\text {th }}$ with a mean score of 2.52 , item 17 which states that as a bereaved spouse, I need to "be safe" ranked $20^{\text {th }}$ with a mean score of 2.51 . Therefore, it can be concluded that bereaved spouses in Nigeria have high priority for psychological and social needs such as the need to get a job to sustain the family, raise finances for family up keep, pay house bills, deal with widowhood isolation, have access to routine medical treatment, and have access to family support, achieve self esteem, have access to regular recreation facilities/opportunities, receive training in order to establish personal projects, remarry, cope with loneliness and to be safe among others. The percentage distribution of bereaved spouse's level of psychosocial needs is presented in Figure 2. 


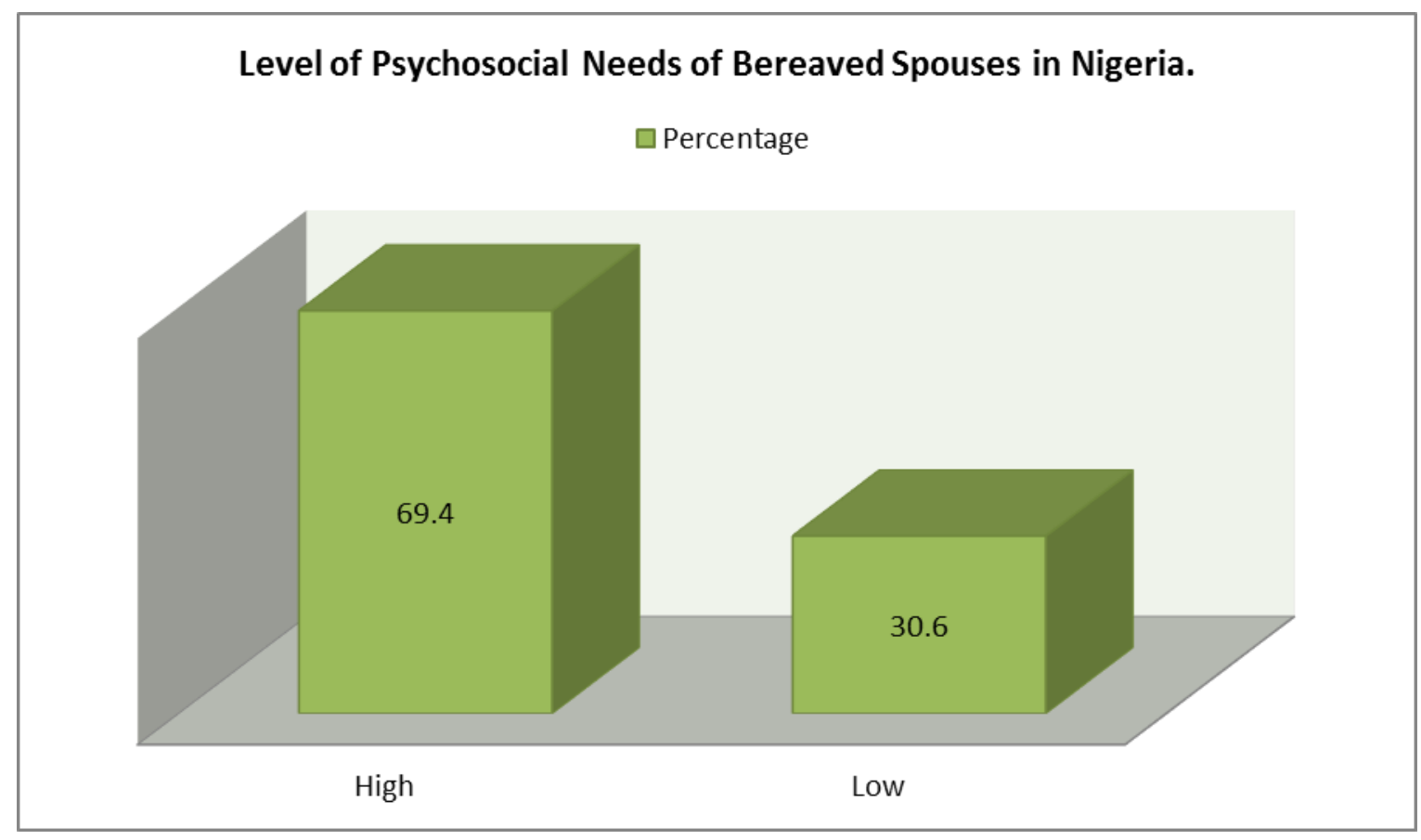

Figure 3: Percentage Distribution of Respondents based on Psychosocial Needs

Figure 3 indicates that 487 (30.6\%) of the respondents had low priority for psychosocial needs, while 1107 (69.4\%) had high priority for psychosocial needs.

\section{Hypothesis 1:}

Psychosocial needs of bereaved spouses in Nigeria will not significantly differ based on age at bereavement.

Table 3: Analysis of Variance (ANOVA) of Psychosocial Needs of Respondents on the Basis of Age at Bereavement

\begin{tabular}{lccccccc}
\hline $\begin{array}{l}\text { Sources } \\
\text { Variance }\end{array}$ & of & $\begin{array}{c}\text { Sums } \\
\text { Squares }\end{array}$ & of & $\begin{array}{c}\text { Mean } \\
\text { Squares }\end{array}$ & $\begin{array}{c}\text { Calculated } \\
\text { F- value }\end{array}$ & Critical F-value & p-value \\
\hline $\begin{array}{l}\text { Between } \\
\text { Groups }\end{array}$ & 925.25 & 3 & 308.41 & $3.35^{*}$ & 2.60 & .02 \\
Within & & & & & & & \\
Groups & 146104.97 & 1590 & 91.89 & & & \\
Total & 147030.22 & 1594 & & & & \\
\hline
\end{tabular}

NB: $*=$ Significant, $\mathrm{p}<0.05$. 
Table 3 presents data on the Analysis of Variance of respondents' psychosocial needs of bereaved spouses on the basis of age at bereavement. The table shows that the calculated F-value of 3.35 is greater than the critical F-value of 2.60 (p-value $.02<0.05$ level of significance). Therefore, the null hypothesis which states that there is no significant difference in the psychosocial needs of bereaved spouses on the basis of age at bereavement is rejected. This means that respondents of different ages at bereavement have different psychosocial needs in Nigeria. A further examination of the group differences was carried out using Duncan's Multiple Range Test (DMRT), a post-hoc test.

Table 4: Duncan Multiple Range Test Showing the Magnitude of Differences in the
\begin{tabular}{lllll} 
Psychosocial Needs of Bereaved Spouses based on Age at Bereavement \\
\hline $\begin{array}{l}\text { Age at } \\
\text { Bereavement }\end{array}$ & Mean & N & Group & $\begin{array}{l}\text { Duncan's } \\
\text { Grouping }\end{array}$ \\
\hline 30 yrs or less & 53.77 & 424 & 1 & $\mathrm{~A}$ \\
Above 50 years & 54.11 & 391 & 4 & $\mathrm{~A}$ \\
31-40 years & 54.34 & 472 & 2 & $\mathrm{~A}$ \\
41-50 years & 55.93 & 307 & 3 & $\mathrm{~B}$ \\
\hline
\end{tabular}

Table 4 shows the magnitude of differences in the psychosocial needs of bereaved spouses based on age at bereavement. The information on the table revealed that group 1 who are respondents that are 30 years or less have slightly different mean scores with group 4 (respondent that are above 50 years) and group 2 (respondents that are 31-40 years) but all the three groups significantly differed from group 3 with a mean score of 55.93. The mean scores of group 3 are greater than the mean scores of all other group. It can thus be concluded that both respondents between 41-50 years of age at bereavement contributed to the differences noted in the ANOVA table 3. The reason for the difference noted may be as a result of the fact that bereaved spouses within this age group are in their exploration stage and would therefore have different needs from other groups.

\section{Hypothesis 2:}

Psychosocial needs of bereaved spouses in Nigeria will not significantly differ based on gender. 
Table 5: Means, Standard Deviations and t-value of Respondents' Psychosocial Needs on the Basis of Gender

\begin{tabular}{lcccclcll}
\hline Gender & No & Mean & $\begin{array}{l}\text { Standard } \\
\text { Deviation }\end{array}$ & df & $\begin{array}{l}\text { Calculated } \\
\text { value }\end{array}$ & t- $\begin{array}{l}\text { Critical } \\
\text { value }\end{array}$ & t- p-value \\
\hline Males & 381 & 54.04 & 9.55 & & 1592 & 0.93 & 1.96 & .351 \\
Females & 1213 & 54.56 & 9.62 & 393 & & & \\
\hline
\end{tabular}

Table 5 presents data on the means, standard deviations and t- value of respondents' psychosocial needs on the basis of gender. The table shows that the calculated t-value of 0.93 is less than the critical t- value of 1.96 (p-value .351>0.05 level of significance). On this basis, the null hypothesis which states that there is no significance difference in the psychosocial needs of bereaved spouses in Nigeria on the basis of gender was accepted. This means that male and female bereaved spouses of do not differ in their psychosocial needs.

\section{Hypothesis 3:}

Psychosocial needs of bereaved spouses in Nigeria will not significantly differ based on religious affiliation.

Table 6: Analysis of Variance (ANOVA) of Respondents' Psychosocial Needs based on Religious Affiliation

\begin{tabular}{|c|c|c|c|c|c|c|}
\hline $\begin{array}{l}\text { Sources of } \\
\text { Variance }\end{array}$ & $\begin{array}{l}\text { Sums of } \\
\text { Squares }\end{array}$ & Df & $\begin{array}{l}\text { Mean } \\
\text { Squares }\end{array}$ & $\begin{array}{l}\text { Calculated } F \text { - } \\
\text { value }\end{array}$ & Critical F-value & p-value \\
\hline $\begin{array}{l}\text { Between } \\
\text { Groups }\end{array}$ & 193.89 & 2 & 96.94 & 1.05 & 3.00 & .35 \\
\hline $\begin{array}{l}\text { Within } \\
\text { Groups }\end{array}$ & 146836.32 & 1591 & 92.29 & & & \\
\hline Total & 147030.22 & 1593 & & & & \\
\hline
\end{tabular}

Table 6 presents data on the Analysis of Variance of respondents' psychosocial needs of bereaved spouses on the basis of religious affiliation. The table shows that the calculated F-value of 1.05 is less than the critical F-value of 3.00 (p-value $.35>0.05$ level of significance). Therefore, the null hypothesis which states that there is no significant difference in the psychosocial needs of bereaved spouses on the basis of religion affiliation was upheld. This means that respondents of different religious affiliation in Nigeria have similar psychosocial needs. 


\section{Hypothesis 4:}

Psychosocial needs of bereaved spouses in Nigeria will not significantly differ based on nature of death.

Table 7: Analysis of Variance (ANOVA) of Psychosocial Needs of Respondents on the Basis of Nature of Death

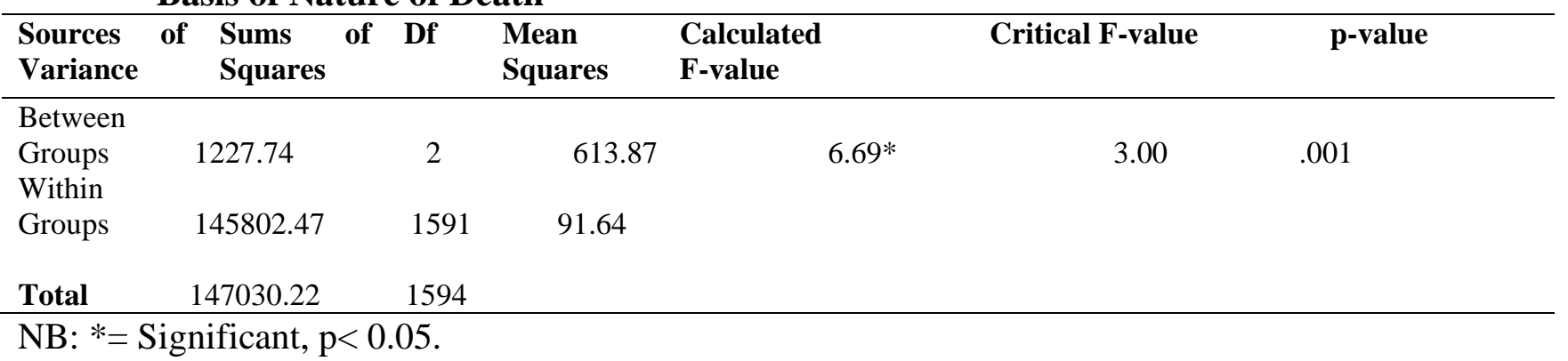

Table 7 presents data on the Analysis of Variance of respondents' psychosocial needs of bereaved spouses on the basis of nature of death. The table shows that the calculated F-value of 6.69 is greater than the critical F-value of 3.00 (p-value $.001<0.05$ level of significance). Therefore, the null hypothesis which states that there is no significant difference in the psychosocial needs of bereaved spouses on the basis of nature of death is rejected. This means that respondents who suffered losses through different nature of death have different psychosocial needs in Nigeria. Since a significant difference was noted, a further examination of the group difference was carried out using Duncan's Multiple Range Test (DMRT), a post-hoc test.

Table 8: Duncan Multiple Range Test Showing the Magnitude of Differences in the Psychosocial Needs of Bereaved Spouses based on Nature of Death

\begin{tabular}{lllll}
\hline Nature of Death & Mean & N & Group & $\begin{array}{l}\text { Duncan's } \\
\text { Grouping }\end{array}$ \\
\hline Others & 54.09 & 370 & 3 & A \\
Anticipated & 53.48 & 562 & 1 & A \\
Sudden & 55.44 & 662 & 2 & B \\
\hline
\end{tabular}


Table 8 shows the magnitude of differences in the psychosocial needs of bereaved spouses based on nature of death. The information on the table revealed that all the groups differed significantly with mean scores of 54.09, 53.48 and 5544 respectively. However, the difference noted in the ANOVA in table 7 is as a result of the fact that group 2 (respondents who lost their spouse to sudden death) contributed more to the significant difference noted in the ANOVA Table 7. This result may be due to fact that the group of spouses who lost their spouses to sudden death is usually caught unaware by the death and in this case they are faced with different psychosocial needs to adapt to the loss.

\section{Hypothesis 5:}

Psychosocial needs of bereaved spouses in Nigeria will not significantly differ based on length of years of loss.

Table 9: Analysis of Variance (ANOVA) of Psychosocial Needs of Respondents on the Basis of Length of Years of Loss

\begin{tabular}{lcccccc}
\hline $\begin{array}{l}\text { Sources } \\
\text { Variance }\end{array}$ & $\begin{array}{l}\text { Sums of } \\
\text { Squares }\end{array}$ & \multicolumn{1}{c}{ Df } & $\begin{array}{l}\text { Mean } \\
\text { Squares }\end{array}$ & $\begin{array}{l}\text { Calculated F- } \\
\text { value }\end{array}$ & Critical F-value & p-value \\
\hline $\begin{array}{l}\text { Between } \\
\text { Groups }\end{array}$ & 1961.61 & 3 & 653.87 & $7.17^{*}$ & 2.60 & .00 \\
$\begin{array}{l}\text { Within } \\
\text { Groups }\end{array}$ & 145068.60 & 1590 & 91.23 & & & \\
Total & 147030.22 & 1594 & & & & \\
\hline
\end{tabular}

NB: *= Significant, $\mathrm{p}<0.05$.

Table 9 presents data on the Analysis of Variance of psychosocial needs of bereaved spouses on the basis of length of years of loss. The table shows that the calculated F-value of 7.17 is greater than the critical F-value of 2.60 (p-value .00<0.05 level of significance). Therefore, the null hypothesis which states that there is no significant difference in psychosocial needs of bereaved spouses on the basis of length of years of loss is rejected. This means that bereaved spouses in Nigeria have different psychosocial needs based on length of years of loss. Since there was a difference in the in the psychosocial needs of respondents in the study, a further examination of the group difference was carried out using Duncan's Multiple Range Test (DMRT) a pot-hoc test. 


\section{Table 10: Duncan Multiple Range Test Showing the Magnitude of Differences in the} Psychosocial Needs of Bereaved Spouses based on Length of Years of Loss

\begin{tabular}{lllll}
\hline $\begin{array}{l}\text { Length of Years of } \\
\text { Loss }\end{array}$ & Mean & N & Group & $\begin{array}{l}\text { Duncan's } \\
\text { Grouping }\end{array}$ \\
Less than a year & 53.32 & 409 & 1 & A \\
6-10years ago & 53.59 & 436 & 3 & A \\
1-5 years ago & 55.25 & 583 & 2 & B \\
Above 10 years & 56.58 & 164 & 4 & B \\
\hline
\end{tabular}

Table 10 shows the magnitude of differences in the psychosocial needs of bereaved spouses based on length of years of loss. The information on the table reveal that groups 1 and 3 who are respondents that have suffered losses less than a year and 6-10 years ago have slightly different mean scores respectively but differed significantly from groups 2 and 4 . Also, group 2 differed significantly from group 4 . The mean score of group 4 is greater than the mean scores of groups 12 and 3. It can thus be concluded that respondents who have suffered losses for more than 10 years ago contributed to the differences noted in the ANOVA table. This implies that bereaved spouses who have lost their loved ones for more than 10 years ago have a different point of view with regards to bereaved spouses' psychosocial needs. Thus, the hypothesis is rejected.

\section{Discussion}

The findings of the study indicated that majority (69.4\%) of bereaved spouses in Nigeria have high priority for psychosocial needs. The study has thus revealed that bereaved spouses in Nigeria need to get a job to sustain the family, raise finances for family up-keep, pay house bills, deal with widowhood isolation, have access to routine medical treatment, have access to family support, achieve self-esteem, have access to regular recreation facilities/opportunities, receive training in order to establish personal projects, re-marry, cope with loneliness and to be safe, among others.

The findings also agree with that of Khaled (2005) who argued that widows are marginalized and do not have any kind of social protection, and therefore advocated the need for development approaches to estimate their needs and help them overcome material and moral thereby through increasing their opportunities and choices and investing their assets and potentials to change their living conditions and improve the quality of their lives. Khaled identified the psychosocial needs of widows to include economic, social, health, educational and psychological needs. The results could be because the bereaved spouse would not need to only adjust to the loss of a close relationship, but may also need to meet certain needs such as handling daily decisions and other responsibilities that were once dispersed between two spouses such as raising finances for family up keep and paying bills. 
The study further revealed that respondents of different ages at bereavement had different psychosocial needs in Nigeria. Based on the result, respondents between 41-50 years of age at bereavement contributed to the differences noted in the study. This finding corroborates the submission of Egbeleye and Oyedeji (2003) that middle age bereaved spouses cope well than old age bereaved spouses because the former are likely to be actively involved in a regular job that would probably provide the required social support network and means of sustenance immediately after bereavement. According to Egbeleye and Oyedeji, these opportunities in most cases do not avail themselves to old age widows who are retired and are most at times lonely because their children are old and are away from home. Young widows are affected in some different ways because they are faced with double challenges; for instance, they grieve both the loss of a companion and the death of their dreams. Accompanying these losses can be the challenges of single parenthood, the need for a career, financial and lifestyle changes, and the readjustment to change of status as in living a life as a single adult. Therefore, the reason for the difference noted in the result may not be unconnected to the fact that bereaved spouses within this age group are in their mid-adult stage characterized by different responsibilities such as rearing children and engaged in full parenting responsibilities as well as building a career.

Furthermore, bereaved spouses of both genders did not differ in their psychosocial needs. The finding of this study may not be unconnected to the fact that death brings additional challenges to both bereaved men and women such as need to cope with new social status, learning to live alone and shoulder the responsibilities that was once shared by two people, managing the properties of the spouse and handling the emotional consequences of losing their spouse. This result does not agree with the findings of Garry, Alfred, Stefoni and Rachel (2001) who submitted that widowhood is more depressing and stressful for men than women. The authors argued that the factors responsible for the stronger effect of widowhood on men included that they have lower frequency of social interaction and religious activity attendance as well as stronger dislike for domestic labor and lessened ability to take care of their children.

Also, respondents of different religious affiliations in Nigeria have similar psychosocial needs. The reason for the finding may be due to the fact that religious organizations are the major places where bereaved spouses received spiritual, social and financial support. This finding agrees with the submission of Wortmann and Park (2008) who posited that a bereaved individual's religious denomination may inform the impact of the loss and his or her way of grieving with it, but so might many other aspects of his or her religious and spiritual life. In addition, religious and spiritual traditions offer different coping resources for dealing with bereavement. These can be in form of social support from Pastors, Imams and fellow congregants. Through these resources, according to Halifax (2008), individuals may find solace and comfort and, over time, work through their grief in ways that allow them to find peace and acceptance and to return to their normal daily lives. Again, many rites and rituals performed in different religions such as prescription of specific prayers and organization of funeral ceremonies to deal with death helps to comfort survivals, give them a sense of belonging to a broader community and assist survivals through the process of grieving. 
More so, respondents who suffered losses through different nature of death have different psychosocial needs in Nigeria. Respondents who lost their spouse to sudden death contributed to the difference noted. This result may be due to the fact that the groups of respondents who lost their spouses to sudden death are usually caught unaware by the death and in this case, they are faced with different psychosocial need to adapt to the loss. This finding corroborates the findings of Maddison and Viola (1968) who conducted a quantitative study on widows whose husbands were between ages 45 and 60 at the time of death and found that spousal bereavement is a risk factor for health deterioration and that women who are bereaved suddenly and without warning are no more likely to suffer ill health than those whose husbands are ill prior to death. Therefore, sudden death may elicit distinctly different health needs.

Finally, there was a significant difference in the psychosocial needs of bereaved spouses in Nigeria on the basis of length of years of loss. This means that bereaved spouses in Nigeria have different psychosocial needs based on length of years of loss. The findings revealed that respondents who suffered loss for more than 10 years back contributed to the differences noted in the study. This implies that bereaved spouses who lost their loved ones for more than 10 years had a different point of view with regard to bereaved spouses' psychosocial needs. This submission is in line with the findings of Hungerford (2001) who worked on economic consequences of widowhood on elderly women and found that death of husband resulted in lower financial status for wives, many of whom became impoverished as a result of bereavement. This finding also agrees with the findings of Zick and Smith (1991) who worked on patterns of economic change surrounding the death of spouse and found that two-fifths of widows fall in to poverty at some time during five years following bereavement and found that people often fall into this situation because they fail to plan for the consequences of spousal loss. Therefore, it appears that financial and other related needs of bereaved spouses vary based on duration of bereavement. This may be due to the fact that economic and financial needs of bereaved spouses, during widowhood is associated with reduced income, increased risk of poverty and increased need of meeting financial responsibility; this is because the death of any of the spouse lead to reduction in the financial status of the surviving partner.

\section{Implications of the Study Findings for Counsellor Training / Practice}

Death is inevitable for all mankind and it is a traumatic experience that poses a lot of threat to the survivors' well-being, especially when it is unexpected. The death of loved ones is ultimately followed by grief reactions which, if not well managed, could lead to poor adjustment and low quality of life. Buoyed by the realization of this fact, bereaved individuals need help in handling their grief reactions in order to cope effectively with their present situation and move ahead with their lives. To achieve this arduous but necessary task, they need the support of helping professionals such as Counsellors to adjust effectively and efficiently to their situation.

Counsellors in collaboration with Non-governmental organizations (NGO'S) need to organize sensitization programmes and focused group discussions as well as bereavement coaching to help grieving spouses adapt to the event of bereavement. The greatest day to day 
challenges of bereaved spouses as found in this study is loneliness caused by the loss of intimate relationship. Counsellors could help grieving spouses to overcome this challenge by encouraging them to engage in meaningful activities that will help them fill the gap left.

The findings of this study revealed that the need to get job to sustain the family is the most prioritized need of bereaved spouses in Nigeria. Counsellors need to look into the causes of financial challenges in widowhood and help clients to develop strategies for handling such challenges. Counselling intervention for bereaved spouses could be tailored towards training for empowerment and financial sustenance and bereavement coping skills in widowhood. More so, as found in this study, bereaved spouses had need to deal with widowhood isolation, access to medical help and social relations. Widowhood in Nigeria has been tagged by many Nongovernmental organizations and government agencies with poverty whereas several factors play major role in individual adjustment because all bereaved spouses are not poor but are devastated by the loss of their partner therefore, they are not in the proper position to handle some commitments. Counsellors need to help this group of people from stigmatization, abuse of human rights and social injustice by providing them with "mind empowerment" instead of the common financial empowerment that is provided by all and sundry.

There is also the need for counsellors to look into the various need of different group of bereaved spouses in the society and provide the needed support based on the peculiarity of each groups. For instance, the findings of this study revealed how variables of gender, age at bereavement, religion and length of years of loss and nature of death influence the grief reactions, psychosocial needs and adjustment strategies of bereaved spouses. The implication of this is that bereaved spouses cannot be treated and given the same form of intervention. Counsellors may need to create several focused groups that will cater for the different challenged bereaved spouses and thus will need to carry out appropriate need assessment before organizing such group.

\section{Conclusion}

Based on the results, it can be concluded that bereaved spouses in Nigeria had high priority for psychosocial needs; the common psychosocial needs of bereaved spouses in Nigeria include the needs to get a job to sustain the family, raise finances for family up keep, pay house bills, deal with widowhood isolation, have access to routine medical treatment, and have access to family support, achieve self-esteem, have access to regular recreation facilities/opportunities, receive training in order to establish personal projects, re-marry, cope with loneliness and to be safe, among others. Also, there were no significant differences in the psychosocial needs of bereaved spouses on the bases of gender and religious affiliations but there were significant differences on the bases of age at bereavement, length of years of loss and nature of death. 


\section{Recommendations}

Based on the results of the study, its discussion and conclusion, the following recommendations are made:

1. Counselling centers and units should not be restricted to schools and hospitals. More center and units should be established in different religious organization and by private practitioner counsellors so that grieving people are assisted and provided with appropriate counselling on issues of adjustment in terms of financial management, emotional stability, social interaction and health management.

2. Counsellors need to provide relevant community-based intervention programmes and support services that will cater for the needs for bereaved spouses of different years of loss. For instance, group of bereaved spouses who lost their spouses between the first five years of loss could be assisted to express their grief, remarry, acquire entrepreneurship skills and with focused group discussions in order to adjust better to their bereavement while those who have lost their spouses for more than 5 years could be assisted to build and harness support systems that would assist them in coping with widowhood.

3. Counsellors need to assist in providing support and advocacy services for the needs of different groups of bereaved spouses based on their characteristics. For instance, younger widows could be provided with services that will help them form new relationship, get enrolled in entrepreneurial skills or job centers to cater for self and family needs while older bereaved spouses could be assisted in having access to regular care, good nutrition and handling loneliness. Counsellors could organize different support programmes for bereaved spouses who suffered loss through varying means of death. 


\section{References}

Barreto, P., Yi, P. \& Soler, C. (2007). Predictors of complicated grief. The Psychologia, 5, (2\& 3), 383-400.

Boyle, P. J., Feng, Z., \& Raab, G. M. (2011). Does widowhood increase mortality risk? Testing for selection effects by comparing causes of spous al death. Epidemiology, 22, 1-5.

BUPA Health Information Services (2004). Bereavement: The process of grieving a loss. Retrieved on $7^{\text {th }}$ March, 2007 from http://www.repsych.ac.uk

Burke, C. T., Shrout, P.E. \& Bolger, N. (2007). Individual differences in the adjustment to spousal loss: A non -linear mixed model analysis. International journal of behavioural Development, 31 (4), 405-415.

Bruce, C. M. (2002). The grief process for patient family and physician. J.A.O. Supplement $3,102(9), 198-204$.

Bruce, M. L., Kim, K., Leaf, P. J., \& Jacobs, S. (1990). Depressive episodes and dysphoria resulting from conjugal bereavement in a prospective community sample. American Journal of Psychiatry, 147, 608-611.

Egbeleye, O. S. \& Oyedeji, M. O. (2003). Bereavement trauma and the coping ability of widow/ers: the Nigerian experience. Journal of Social Science, 7(4) 249-254

Garry, R. L., Alfred, D., Stefoni, B. \& Racheal S. (2001). Gender differences in the depressive effect of widowhood in later life. Journal of Gerontology 56 B(1) 56-61.

Halifax, J. (2008). Being with dying: Cultivating compassion and fearlessness in the presence of death. Boston: Shambhala.

Hansson, R., \& Stroebe, M. (2007). Bereavement in late life. Washington DC: American Psychological Association.

Hungerford, T. L. (2001). The economic consequences of widowhood on elderly women in the United States and Germany. The Gerontologist, 41(1), 103-110.

International Organization for Migrations. (2010). Psychosocial need assessment in emergency, displacement, recovery and return. IOM tool, Geneva, Switzerland.

James, P.Y. (2010). Research design in occupational education. Oklahoma: Oklahoma State University Press. 
Khaled, F.S. (2005). Widow needs assessment case study of North Cairo. Social Units Partnership in Development Research, 44, 31-38.

Maddison, D., \& Viola, W. (1968). Factors affecting the outcome of conjugal bereavement. British Journal of Psychiatry, 113, 1057-1067.

Maslow, A. H. (1954). Hierarchy of needs motivational model. Alan Chapman review and other material. New York: Harper.

National Bureau of Statistic (2012). Annual abstract of statistics of the federal republic of Nigeria. Retrieved December 14, 2015 from http://www.nigerianstat.gov.ng

Monk, T. H., Begley, A. E., Billy, B. D., Fletcher, M. E., Germain, A., Mazumdar, S. \& Zarotney, J. R. (2008). Sleep and circadian rhythms in spousally bereaved seniors. Chronobiology International, 25(1), 83-98.

Phillips, A.C., Carroll, D., Burns, V. E., Ring, C., Macleod, J., \& Drayson, M. (2006). Bereavement and marriage are associated with antibody response to influenza vaccination in the elderly. Brain, Behaviour, and Immunity, 20, 279-289.

Prigerson, H. G., \& Jacobs, S. (2001). Traumatic grief as a distinct disorder: A rationale, consensus criteria, and a preliminary empirical test. In M.S. Stroebe, R.O. Hansson, W. Stroebe \& H. Schut (Eds.), Handbook of bereavement research: Consequences, coping, and caring (pp.613-641). Washington, DC: American Psychological Association.

Prigerson, H. G., Vanderwerker, L. C, \& Maciejewski, P. K. (2008). A case for inclusion of prolonged grief disorder in DSM-V. In M.S. Stroebe, R.O. Hansson, H. Schut, \& W. Stroebe (Eds.), Handbook of bereavement research and practice: Advances in theory and intervention (pp.165- 186). Washington, DC: American Psychological Association.

Tomarken, A., Holland, J., Schachter, S., Vanderwerker, L., Zuckerman E., \& Nelson C. (2008). Factors of complicated grief pre-death in caregivers of cancer patients. Psychooncology, $17,105-111$.

Wortmann, J. H., \& Park, C. L. (2008). Religion and spirituality in adjustment following bereavement: An integrative review. Death Studies, 32, 703-736.

Zick, C. \& Smith, K. (1991). "Patterns of Economic Change Surrounding the Death of a Spouse”, Journal of Gerontology: Social Sciences, 46 (6), 310-320 